\title{
Synaptic Connectivity Between Cricket Auditory Interneurons as Studied by Selective Photoinactivation'
}

\author{
ALLEN I. SELVERSTON, ${ }^{2}$ HANS-ULRICH KLEINDIENST, AND FRANZ HUBER \\ Max-Planck-Institut für Verhaltensphysiologie, Abteilung Huber, D-8131 Seewiesen, Federal Republic of Germany
}

\begin{abstract}
Sound detection and localization are important for crickets. Interneurons located in the prothoracic ganglion play a crucial role in the initial processing of the auditory inputs. Two of the most readily recorded and dye-marked auditory interneurons in the prothoracic ganglion of the cricket are the omega cells $(O N / 1)$ and the ascenders $(A N / 2)$. By using a new photoinactivation technique to selectively inactivate these cells, the synaptic relationship between them could be studied. Our results indicate that the $\mathrm{ON} / 1$ cells are connected to each other with reciprocal inhibitory synapses. An ON/1 cell responds to contralateral stimulation with strong inhibition mediated by the other ON/ 1 cell. When one cell is killed, this inhibition is removed, and a weak excitatory response is unmasked. Unlike the ON/ 1 cell, AN/ 2 produces an inhibitory response when stimulated ipsilaterally to the cell body side, and this response is also removed when the ipsilateral ON/1 cell is killed, providing strong evidence that $\mathrm{ON} / 1$ is the source of the inhibition. As with the $O N / 1$, the inhibition is replaced by weak excitation.
\end{abstract}

A family of mirror-image neuron pairs in the cricket prothoracic ganglion performs the initial stages of processing auditory input (Wohlers and Huber, 1982; Atkins et al., 1984). These neurons provide information used for recognition of the species-specific calling song and its localization in space (see Huber, 1983, and Boyan, 1984, for a review of the literature). In order to assess the individual importance of such cells in this processing, we have examined the connectivities and functional relationships between two of the most readily recorded and marked types, the intraganglionic cell type, $O N / 1$, and the ascending cell type, $A N / 2$. The latter is one of several types of ascenders which transmit the initially integrated information to the head ganglia (Stout and Huber, 1972 1982; Rheinlaender et al., 1976; Boyan and Williams, 1982; Schild berger, 1984). The anatomy and physiology of these neurons within the prothoracic ganglion has already been described in some detail (Cassaday and Hoy, 1977; Popov et al., 1978; Wohlers and Huber, 1978, 1982; Wiese, 1981; Kleindienst et al., 1981; Popov and Markovich, 1982; Hoy et al., 1982; Moiseff and Hoy, 1983; Boyd et al., 1984; Kühne et al., 1984), after their original discovery by Popov

Received August 20, 1984; Revised October 23, 1984;

Accepted October 26, 1984

${ }^{1}$ This work was supported by the Alexander von Humboldt Foundation through an Award for Senior U. S. Scientists given to A. I. S. We thank Mrs. Sylvia Schmaderer for invaluable technical help and Mrs. Heidrun Bamberg for photographic assistance

${ }^{2}$ Present address: Department of Biology, B-022, University of California, San Diego, La Jolla, CA 92093, U.S.A. (see Elsner and Popov, 1978). The first complete anatomical description of AN/2 is given by Schildberger (1984).

However, several important questions concerning the detailed physiological interactions between these neurons are still to be addressed. In particular, the existence of reciprocal inhibition between the two $\mathrm{ON} / 1$ cells has not been investigated by dual intracellular recordings, although these cells are thought to play an important role in sharpening binaural contrast for sound source localization (Cassaday and Hoy, 1977; Popov et al., 1978; Kleindienst et al., 1981; Wohlers and Huber, 1982) and/or form the initial stages of sound pattern recognition (Wiese, 1978, 1983, 1984). Furthermore, it is still not known how the $\mathrm{ON} / 1$ cells act upon other auditory interneurons-for instance, the ascender cells which carry pattern and directional information to the head ganglia.

Recently, it has become possible to study the connectivity between neurons by making single cell ablations with a photoinactivation procedure, and see the effects these perturbations have on normal circuitry (Miller and Selverston, 1979). Wo have employed this technique on the cricket auditory pathway to study both reciprocal inhibitory interactions between the ON/1 type cells and to see if the source of inhibition found in AN/2 type cells is from the ON/ $1 \mathrm{s.}$

\section{Materials and Methods}

Unless stated otherwise, experiments were performed on female crickets Gryllus bimaculatus DeGeer 2 to 4 weeks after adult moult. The animals were mounted, ventral side up, on a Plexiglass stand; the prothoracic ganglion was then exposed. The large tracheal tube, connecting the two ears, was cut on both sides of its medial septum, and the large prothoracic spiracles were routinely covered with wax. The forelegs, containing the ears were placed in small sound cavities bearing small speakers (Fig. 1). With this method, the ears could be stimulated separately, and acoustic cross-talk in the auditory system was reduced by as much as $60 \mathrm{~dB}$ (for technical details of the legphone system, see Kleindienst et al., 1981).

The ears were stimulated acoustically with artificial calling chirps consisting of four syllables (syllable duration, 16 to $22 \mathrm{msec}$, including rising and falling ramps of $2 \mathrm{msec}$; syllable period, $30 \mathrm{msec}$; carrier frequency, $5 \mathrm{kHz}$ ) presented twice per second. Sound pressure levels could be varied between 40 and $95 \mathrm{~dB}$ RMS in increments of $5 \mathrm{~dB}$. Stimuli are labeled ipsilateral (contralateral) if the activated ear was ipsilateral (contralateral) to the side of the cell body of the cell being studied (Wohlers and Huber, 1982).

Electrophysiological recordings from acoustic neurons in the prothoracic ganglion were made intracellularly using glass capillary microelectrodes filled with $3 \%$ Lucifer Yellow dissolved in $1 \mathrm{M} \mathrm{LiCl}$. Electrode resistances measured 60 to 150 megohms. Experimental data were stored on tape (Racal Store 4DS). All neurons studied were stained with Lucifer Yellow for identification and/or photoinactivation. Selective cell ablation was performed by irradiating the prothoracic ganglion with intense blue light from a Krypton laser (Coherent Innova 90K). Beam power ranged from 5 to $50 \mathrm{~mW}$, corresponding to an average light intensity of 4.4 to $44 \times 10^{3} \mathrm{Jm}^{-2} \mathrm{~s}^{-1}$. Figure 2 shows the time course of a low power kill $(5 \mathrm{~mW})$ of an acoustic interneuron ON/1. Higher power illumination $(50 \mathrm{~mW})$ reduced the time required for cell killing to some $10 \mathrm{sec}$. Visual confirmation of the filled cells was made by observing them in situ through a dissecting microscope with a yellow barrier filter (GG 475). 


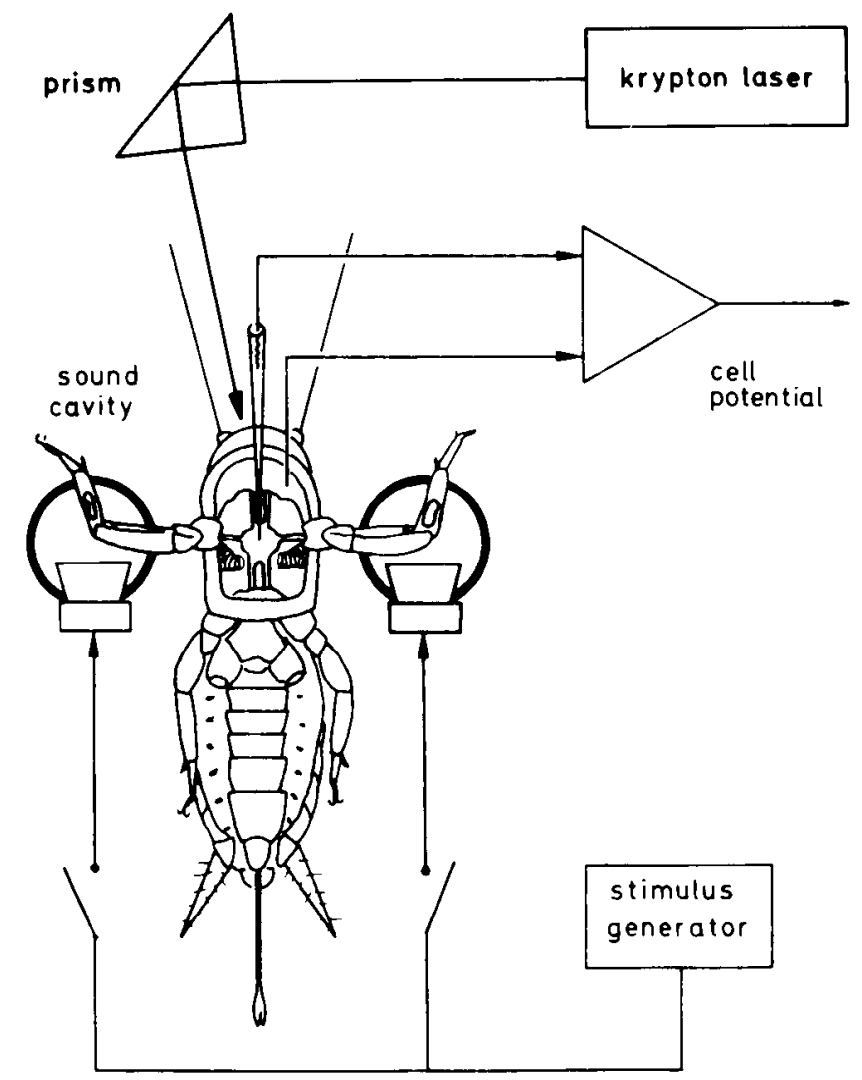

Figure 1. Experimental set-up for recording, stimulating, and ablating cells in the cricket central nervous system. The animal is mounted ventral side up onto a perspex block and hold in place with wax. Each foreleg is mounted in an acoustic chamber containing a miniature speaker. Artificially generated calling songs could be delivered in each foreleg hearing organ independently from the stirmulus gerıeralor. The prothoracic ganglion was supported by a metal spoon which effectively immobilized it for intracellular recordings. The laser beam, used to photoinactivate Lucifer Yellow filled cells, was directed downward to the ganglion by means of an adjustable prism. A barrier fitter built into the stereo dissecting microscope permitted observation of the filled cell during periods of illumination.

Cells were photographed after the ganglia were fixed in phosphate-buffered formaldehyde, dehydrated in alcohol, and cleared in methyl benzoate.

\section{Results}

The physiology of the large intraganglionic $\mathrm{ON} / 1$ cells has been described for Gryllus campestris by Wohlers and Huber (1978, 1982). Important additional information has been provided for Gryllus bimaculatus by Popov et al. (1978) and Wiese (1978, 1981, 1983, 1984). We will review this information briefly.

Each $O N / 1$ cell is made up of two bilateral neuropil segments (Fig. 3A). A cell body with a neurite and a connecting segment (axon), rostral to the fine branches of both neuropil segments, gives the overall structure of the cell an $\Omega$ shape. The fine branches are located in what is usually called the acoustic neuropil (Eibl and Huber, 1979). Those fine processes which are ipsilateral to the cell body are probably contacted by primary efferent auditory fibers coming from the ear located in the ipsilateral front leg. When these afferents are activated by sound received at the tympanal organ with sufficient intensity, firing of the $O N / 1$ is produced; if the sound is made up of syllables and chirps similar to the natural calling song, the $\mathrm{ON} / 1$ fires in bursts of spikes (Fig. 3B), the number depending upon sound intensity and the bursts following the pattern structure of the song. The spikes, which are generated on the cell body side, i.e., ipsilateral, are then transmitted without failure to the contralateral side (Wohlers, 1980). They are superimposed on summed EPSPs, and the ratio of spike amplitude to summed EPSP amplitude in- creases with increasing distance of the recording site from the spike generating zone (Fig. $3, B$ and $D$; and see also Wohlers and Huber, 1978). In the experimental situation (called closed field stimulation, Kleindienst et al., 1981) in which artificial calling songs can be played into each ear separately, it can be shown that when sound is delivered only to the ear contralateral to the cell body and the acoustic trachea is cut, the $\mathrm{ON} / 1$ cell responds with bursts of inhibitory potentials (Fig. 3C) (Wohlers and Huber, 1978, 1982; Kleindienst et al., 1981). By stimulating the ipsilateral ear to some constant level of response, Kleindienst et al. (1981) have shown that increasing the intensity to the contralateral ear reduces the number of spikes produced in $\mathrm{ON} / 1$. This reduction in activity was postulated to result from inhibition mediated by the partner ON/ 1 cell (Wohlers, 1980 ); i.e., there is indirect evidence that the ON/1 pair may be connected to each other via reciprocal inhibitory synapses.

Demonstration of reciprocal inhibition in $\mathrm{ON} / 1$ cells. Simultaneous dual intracellular recordings from a pair of $\mathrm{ON} / 1$ cells is shown in Figs. 4 to 6 . In this particular example, one of the $O N / 1$ neurons (upper traces in Figs. 4 and 5) responded to auditory stimuli from the ipsilateral side in the conventional way with bursts of spikes superimposed on summed EPSP activity. The other ON/1 (lower traces in Figs. 4 and 5), however, did not respond to auditory stimulation of the corresponding ear for unknown reasons. This cell exhibited spontaneous firing during the interchirp pauses which was interrupted by marked inhibitory responses related to the excitatory responses of the partner cell (Fig. 4, $A$ and $B$ ). The spikes produced between chirps, however, caused strong inhibitory responses in the partner cell, indicating reciprocal inhibition between the two ON/ 1 cells. Since the second cell did not respond to ipsilateral stimulation, unilateral and bilateral stimulation (Fig. 4, $A$ and $B$ ) showed similar responses. When both ears were stimulated, the responsive cell (upper traces) displayed the typical spike pattern characteristic of ipsilateral stimulation, while the unresponsive neuron (lower traces) showed what appeared to be monosynaptic inhibitory postsynaptic, potentials following $1: 1$ the spikes elicited during the calling chirp. The nonresponsive cell fired spontaneously without sound being delivered to the ears, and clear, short latency IPSPS could be seen in the partner cell following each of these spikes (Fig. 4C).

Manipulation of the membrane potentials of the two ON/1 cells by passing current through the microelectrodes suggests the chemical nature of these synaptic connections. In Figure 5, cell 1 is left at the normal resting potential and is silent except when activated by an ipsilateral sound puise (Fig. 5, middle trace). Cell 2 has been hyperpolarized past its reversal potential to suppress spontaneous activity so that inhibitory potentials appear in a depolarizing direction. During strong depolarization of cell 1 , the hyperpolarized cell 2 exhibits a shift of membrane potential in the depolarizing direction.

Further details of the inhibitory connections between the two cells can be seen in Figure 6. As already mentioned, when one ON/1 is stimulated with an artificial calling song delivered to its ipsilateral ear, time-locked IPSPS, following at very short intervals (<msec) can be seen in the second ON/1. Furthermore, spontaneous spikes in the second cell produce similar short latency unitary IPSPs back onto the first cell. As shown in Figure 6A, the first cell (cell 1: upper trace) can be made to fire more or less tonically with passage of depolarizing current when the auditory stimulus is turned off. If, under these conditions, the second cell (cell 2: lower trace) is hyperpolarized beyond the point of the reversal potential, unitary but inverted IPSPS can also be seen. When the first cell is hyperpolarized slightly (Fig. $6 B$ ) so that the responses to ipsilateral stimulation are slightly reduced and the second cell is returned to its resting level, some of the depolarizing potentials (seen between the second and third chirp in Fig. $6 B$ and indicated by arrows, upper trace) are coincident with IPSPS in the second cell (arrows, lower trace). This result is very suggestive, although not conclusive, evidence for the possibility of an additional nonspiking transmission between the two cells.

Removal of inhibition by killing one ON/1 cell. The short latencies between spikes in one $\mathrm{ON} / 1$ and postsynaptic potentials in the other 
$\mathrm{mV}$

$$
\left.\begin{array}{c}
80 \\
40 \\
0
\end{array}\right]
$$

$\left.\begin{array}{c}80 \\ 40 \\ 0\end{array}\right]$

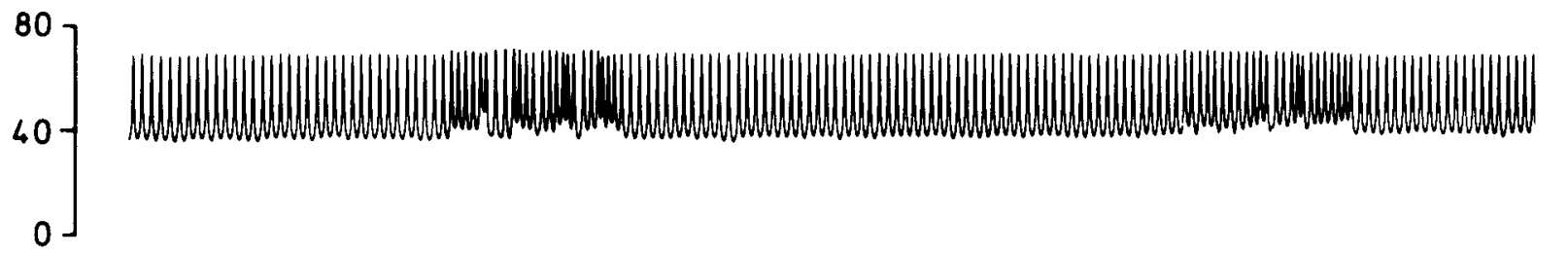

$94 \mathrm{sec}$
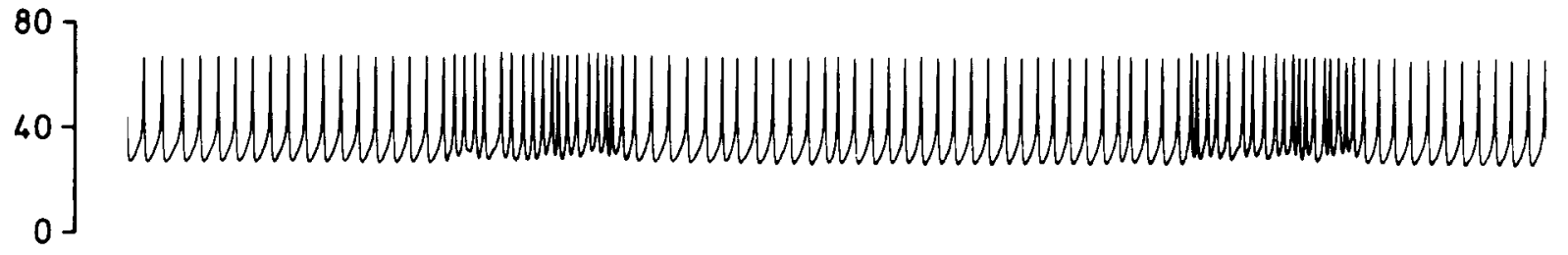

$88 \mathrm{sec}$

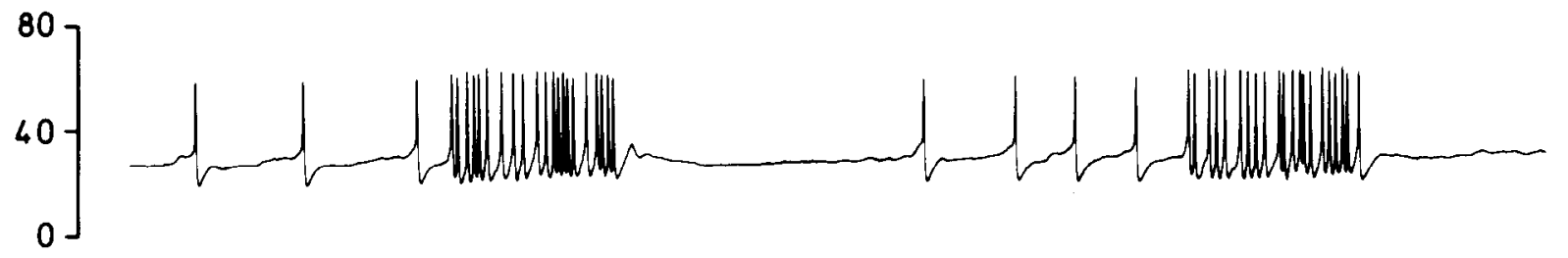

$83 \mathrm{sec}$

$\left.\begin{array}{l}80 \\ 40 \\ 0\end{array}\right]$

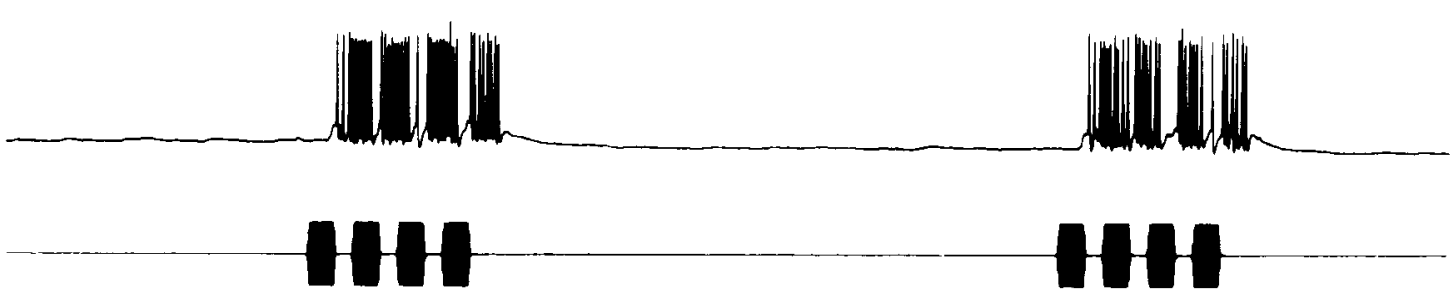

$0 \mathrm{sec}$

sound

\section{$200 \mathrm{~ms}$}

Figure 2. Time course of a photoinactivation procedure. Intracellular recordings taken at $5 \mathrm{kHz} 85 \mathrm{~dB}$ from a stimulated ON/1 cell during the photoinactivation show a progressive decrease in membrane potential and disappearance of the excitatory response. In this example, the cell was killed after approximately $2 \mathrm{~min}$ of irradiation, but this time period varied from cell to cell depending upon the concentration of dye within the cell and the intensity of the illumination.

$\mathrm{ON} / 1$ and the $1: 1$ relationship suggest monosynaptic connections between the two cells, as already postulated by Wohlers (1980) without direct evidence. A further indication that this is a direct connection can be obtained by showing that the IPSPS normally observed during contralateral stimulation are removed when the ipsilateral cell is killed. As before, this does not conclusively prove monosynapticity, since it cannot be excluded that an intermediary neuron would also be affected.

In Figure 7, responses to acoustic stimuli in a right $\mathrm{ON} / 1$ are shown before and after the left $\mathrm{ON} / 1$ is killed by photoinactivation. The strong inhibition (Fig. 7B) mediated by contralateral stimulation became weaker (Fig. 7, C and D) and disappeared (Fig. 7, $D$ to $F$ ) during the killing procedure. The spontaneous discharge rate of the right $\mathrm{ON} / 1$ is temporarily reduced (Fig. $7, C$ to $E$ ) but finally rises again to its initial level (Fig. $7, B$ and $F$ ). So far, the response changes in the recorded ON/ 1 cell are compatible with what can be expected from the kinetics of the response in the cell being killed. As shown in Figure 2, the stimulus-related response of ON/1 and hence its inhibitory effect on the partner cell is gradually reduced during the killing procedure. The spontaneous discharge rate, however, increases continuously, and the inhibitory effect that can be expected from such activity should rise until it finally disappears completely 


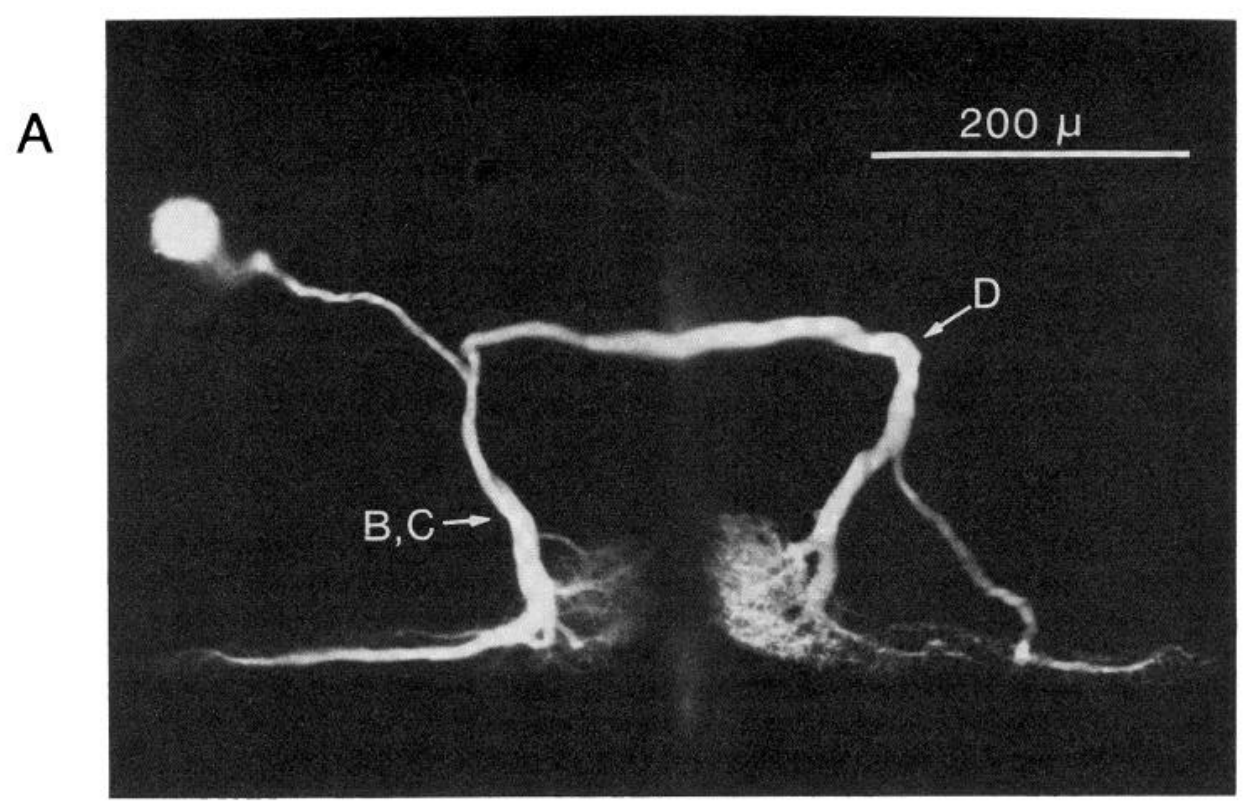

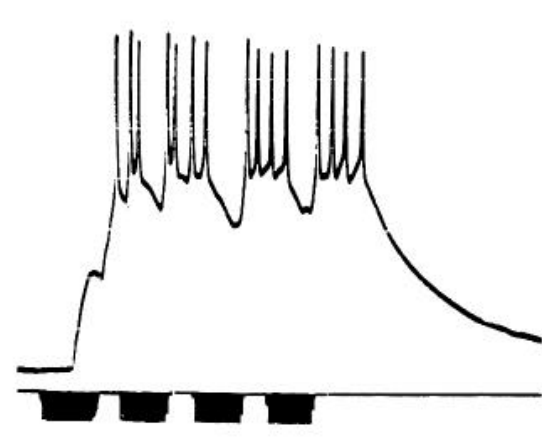

B

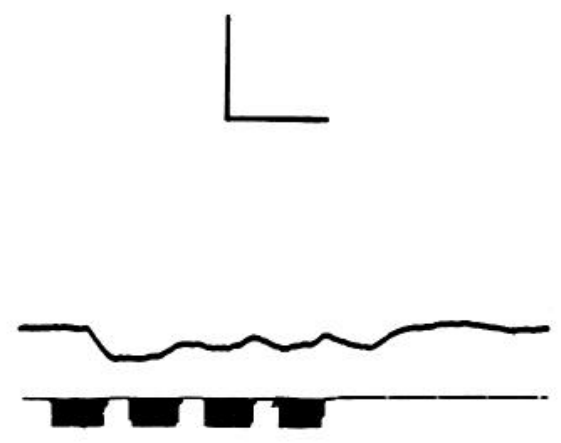

C

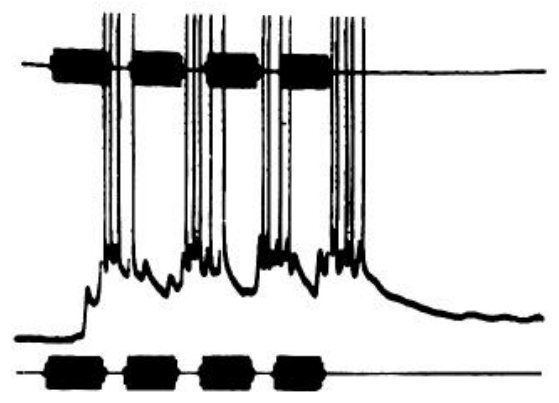

D

Figure 3. Morphology and auditory responses of the $\mathrm{ON} / 1$ neuron. $A$, Lucifer Yellow fill of an $\mathrm{ON} / 1$ cell. $B$ to $D$, Intracellular recordings from three different preparations. Artificial calling songs of four syllables, having a carrier frequency of $5 \mathrm{kHz}$ and an intensity of $85 \mathrm{~dB}$, were delivered separately to each foreleg. Intracellular recordings made from the side of the neuron ipsilateral to the cell body show attenuated spikes riding on large postsynaptic potentials when the stimulus is delivered to the same side. $B$, Contralateral stimulation, however, causes inhibition of the cell, as shown in $C$. Recordings made from the output side of the cell $(D)$ show much smaller PSPs but larger spikes when both ears are stimulated. Electrode positions are shown in $A$. Calibration bars, $20 \mathrm{mV}$ and $40 \mathrm{msec}$.

with increasing depolarization of the cell. A surprising result of the killing procedure was that instead of complete nonresponsiveness to contralateral stimulation, the surviving $\mathrm{ON} / 1$ cell displayed a slight excitatory response (Fig. 7, $D$ and $E$ ). This response was manifested by a small shift in the base line in the depolarizing direction and by an increase in spike frequency during sound stimulation of about 30 to $40 \%$ compared to the resting discharge. Since the large acoustic trachea connecting the two hearing organs was routinely cut for these experiments, sound transduction to the contralateral ear was reduced by some $60 \mathrm{~dB}$. Therefore, activation of primary afferents of that ear is very unlikely. A second example showing the effect of killing one $\mathrm{ON} / 1$ cell on the acoustic responsiveness of the other is given in Figure 8. Here also the effect of the photoinactivation is to remove contralateral inhibition.

Physiology of AN/2 Cells. The AN/2 neurons, one type of the group of ascending plurisegmental interneurons in the cricket auditory pathway, were first described by Stout and Huber (1972) and referred to as chirp coders. They were studied later by Rheinlaender et al. (1976) using brain recordings and were restudied by Stout and Huber (1981) with recordings made in the cervical connectives. The first anatomical description within the prothoracic ganglion was given by Cassaday and Hoy (1977) for Teleogryllus oceanicus, but details of the anatomy in other Gryllid species were worked out by Wohlers and Huber (1978, 1982) and by Popov and Markovich (1982). Recently, Boyd et al. (in press) and Hutchings and Lewis (1984) have provided evidence that several classes of AN/2 neurons may exist, distinguishable by their physiological responses to auditory stimulation. However, all AN/2 neurons encountered so far are anatomically consistent-characterized by a large process with fine side branches running parallel to the path of incoming auditory fibers and covering part of the acoustic neuropil (Fig. 9A). The cell body is located contralateral to this process and connected to it by a thin neurite crossing the midline. Near the midline but still contralateral to the cell body, a second large process, the axon, branches off, proceeds rostrad, and terminates in the brain (Rheinlaender et al., 1976; Boyan and Williams, 1982). There, it contacts brain neurons presynaptically (Boyan, 1980, 1981; Schildberger, 1983).

Unlike ON/1 cells, the AN/2 neurons are somewhat more variable in their responses to auditory stimuli (Wohlers and Huber, 1982; Popov and Markovich, 1982). Despite this variability, the most common finding is that AN/2 neurons in Gryllus campestris and Gryllus bimaculatus are only slightly excited or compłetely inhibited 


\section{ON/1 PAIR}

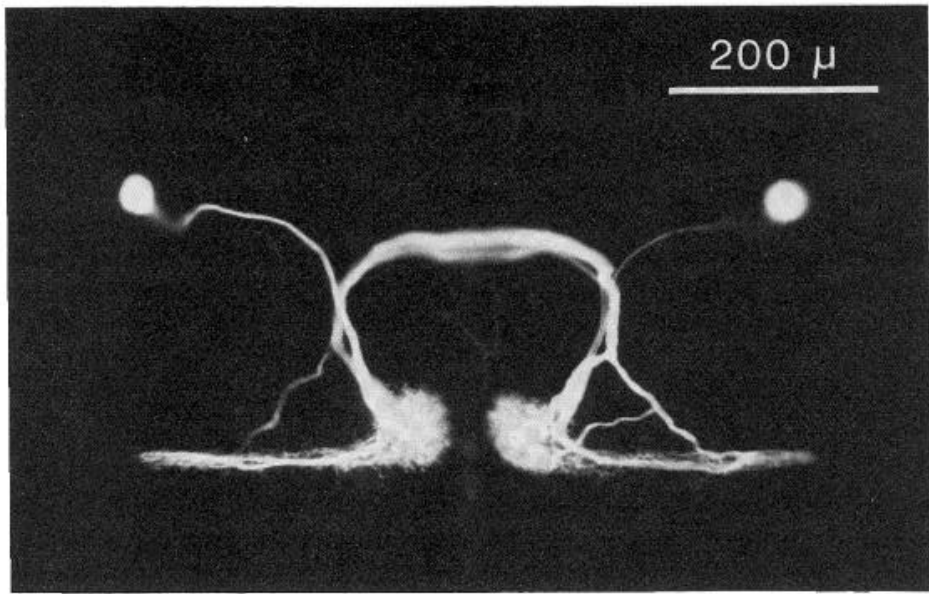

A
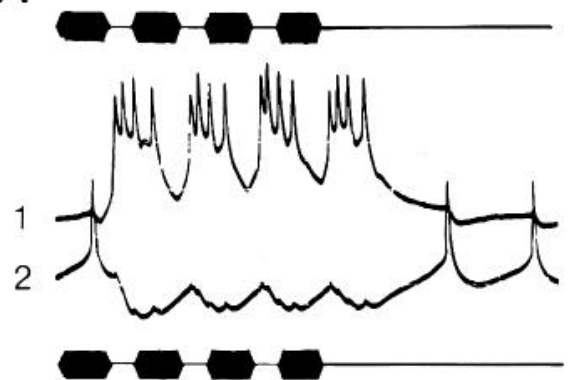

B
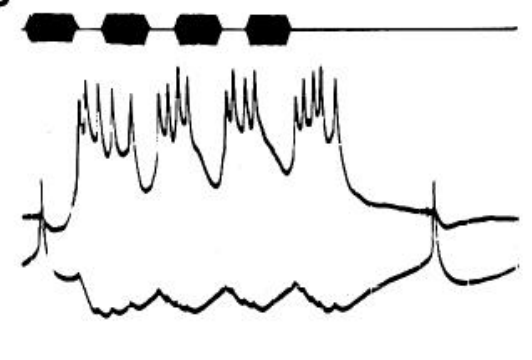

C

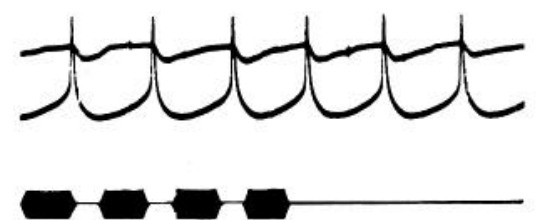

Figure 4. Dual intracellular recordings from a pair of ON/1 neurons. In this preparation, excitatory input into cell 2 was blocked. Under these conditions, artificial calling songs at $5 \mathrm{kHz}$ and $85 \mathrm{~dB}$ applied to both ears produced bursts of spikes in cell 1 and inhibition in cell $2(A)$. The same can be seen in $B$, where the stimuli are applied ipsilateral to cell 1 only. Stimulating the side ipsilateral to cell $2(C)$ shows no response to the stimuli, but spontaneous spikes in cell 2 reveal short latency IPSPs in cell 1. Calibration bars, $20 \mathrm{mV}$ and $40 \mathrm{msec}$.

cell 1

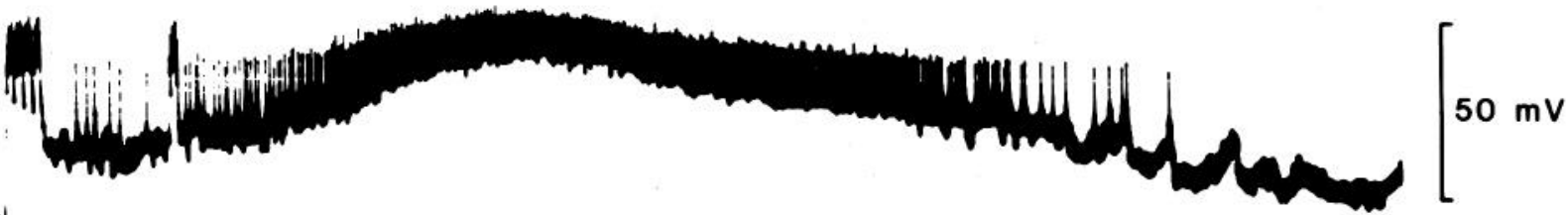

Anm

sound

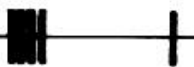

cell 2

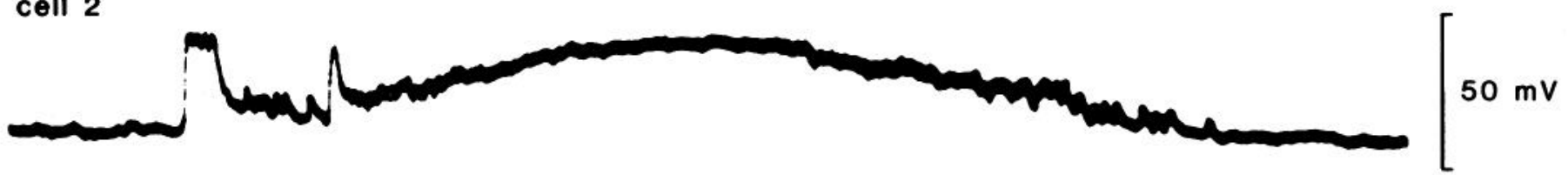

\section{$0.5 \mathrm{~s}$}

Figure 5. ON/1 interactions as revealed by sound and current stimulation. Excitation of one omega neuron (cell 1) with sound or depolarizing current leads to a depolarizing response in its partner neuron (cell 2) which has previously been hyperpolarized past its IPSP reversal potential. 
A

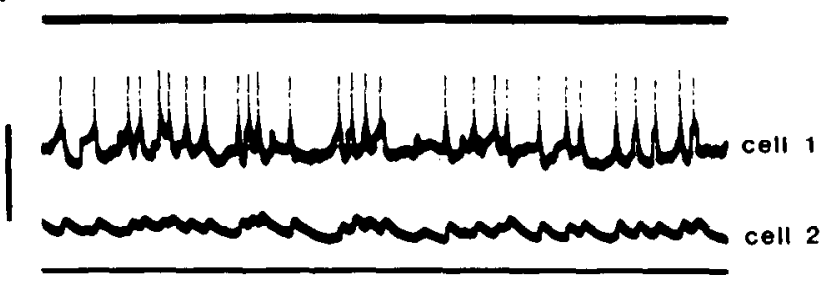

B

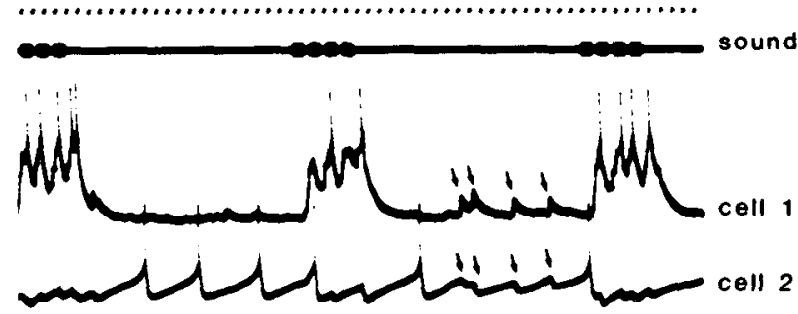

Figure 6. Dual recordings from a pair of $0 N / 1$ neurons. $A$ shows spontaneous firing of cell 1 induced by passage of depolarizing current Cell 2 has been hyperpolarized past the IPSP reversal potential so that the IPSPS are inverted. Note the $1: 1$ relationship between these potentials and the spikes. In $B$, cell 1 has been hyperpolarized slightly so that the responses to artificial calling songs $(5 \mathrm{kHz}, 85 \mathrm{~dB})$ are reduced and spontaneous potentials between stimuli do not reach threshold. Under these circumstances, "abortive spikes" in cell 1 coincide with IPSPS in cell 2 (arrows). Time marks are 20 msec; vertical calibration is $35 \mathrm{mV}$.

by stimulation ipsilateral to the cell body side (Fig. 9C). They sometimes give only a weak excitatory response to contralateral stimulation in the $5 \mathrm{kHz}$ range or are strongly excited, as shown in Fig. 9B. Binaural stimulation (Fig. 9D) elicits responses most commonly comparable to contralateral stimulation (see Wohlcrs and Huber, 1982). Apparently the influence of strong ipsilateral inhibition (Fig. 9C) is not expressed in the response to the combined ipsi- and contralateral stimulation. When stimulated with calling songs, AN/2 neurons in Gryllus differ from the ON/1s in that they do not follow the individual syllables of the chirp with high fidelity, i.e., with syllable correlated bursts of spikes, but instead fuse the spikes into continuous bursts encoding the chirp (Fig. $9, B$ and $D$ ).

Effect of Killing $O N / 1$ on AN/2. Since directional responsiveness, as indicated by ipsilateral inhibition and contralateral excitation (Fig. 9 ), is evident, we hypothesized that the ipsilateral inhibition may be due to input from that ON/ 1 which is excited on the ipsilateral side of $A N / 2$, but with the output region overlapping the lateral process of AN2, as shown in Figure 10. Excitation of AN/2 by contralateral stimulation is thought to be mediated via primary auditory fibers or perhaps by some intervening neuron which is not $\mathrm{ON} / 1$.

In order to test this hypothesis, an $\mathrm{ON} / 1$ neuron was identified physiologically and filled with Lucifer Yellow but not irradiated. Subsequently, an AN/2 neuron whose cell body was on the same side as that of the filled ON/1 was penetrated (Fig. 10A). The resporisiveriess of the AN/2 auditory stimulation was then examined both before and after killing the $\mathrm{ON} / 1$ cell. Before photoinactivation of the ON/1 cell, the AN/2 cell showed an excitatory response to contralateral stimulation (Fig. 10B) and a transient inhibitory response to ipsilateral stimulation (Fig. 10C). After killing the ON/1 (Fig. 10D), the response to ipsilateral stimulation at the same frequency and intensity now revealed removal of the inhibition and the presence of excitation. Here, the strength of sound-induced excitation (increase of the firing rate by about $50 \%$ ) may be enhanced by the current state of cell depolarization.

In order to see if $A N / 2$ played any role in inhibiting $O N / 1$, the reverse of the previous experiment was performed; i.e., an AN/2 cell was filled but not irradiated, and this was followed by recording the inhibitory response in the ipsilateral $\mathrm{ON} / 1$ before and after the AN/2 was killed. Since the AN/2 responds to contralateral stimulation with an excitatory response, it is entirely conceivable that it may have synaptic input onto the $\mathrm{ON} / 1$ in the same manner that the $\mathrm{ON} / 1$ does. However, removal of the AN/2 (Fig. 11) appeared to have no measurable effect on the ON/ 1 inhibitory response, and we therefore conclude tentatively that no interaction in this direction exists. It is possible any effect could be masked by the strong $\mathrm{ON} / 1$ inhibition, so further experiments in which the other $\mathrm{ON} / 1$ is also killed are needed.

\section{Discussion}

ON/1-ON/1 Interactions. Excitation of ON/1 celis when stimulated from the side ipsilateral to the cell body and inhibition when stimulated from the contralateral side (Wohlers and Huber, 1978; Kleindienst et al., 1981) led to the postulate that this inhibition is mediated by the partner ON/1 cell (Wohlers, 1980). However, clear proof supporting this postulate was missing. The simultaneous dual penetration of the ON/1 pair, as well as the cell killing experiments, provide for the first time strong evidence that the reciprocal inhibition between these cells is monosynaptic. At present, the strongest evidence for this monosynapticity is the very short latency between a spike in the presynaptic ON/1 and an IPSP in the postsynaptic $\mathrm{ON} / 1$ which is consistent with a single synapse. More rigorous tests for monosynapticity such as injection of tetraethyl ammonium into the presynaptic cell or elevation of the Ca concentration of the bath saline would yield more definite results.

The dual penetration also showed that there exists a possibility for nonspiking transmission between the two ON/1 cells. To date, no source of inhibition onto the ON/1s has been described other than the contralateral member of the pair. Therefore, IPSPs in one $\mathrm{ON} / 1$ which were clearly coincident with subthreshold excitatory responses in the other could result from such graded transmission. Since there are now many examples of graded transmitter release by insect interneurons (Pearson and Fourtner, 1975; Burrows and Sicgler, 1978; Burrows, 1979, 1983) the fact that such interactions may exist between $\mathrm{ON} / 1 \mathrm{~s}$ is not altogether surprising. However, one must keep in mind that the $\mathrm{ON} / 1 \mathrm{~s}$ do generate all-or-none action potentials, as do other local or intraganglionic interneurons in the cricket auditory pathway (Boyan, 1980, 1981; K. Schildberger, submitted for publication), in spite of their small size and the close proximity between input and output processes. This raises the more general question; namely, what are the evolutionary advantages of spiking versus nonspiking neurons, a question which is not yet answered (Burrows, 1983).

There is still another possible explanation for the observed coincidence between subthreshold responses in one ON/1 and IPSP responses in the other $\mathrm{ON} / 1$. Both activities could be elicited by some as-yet-undescribed element. Such an element would have to provide common input to both $\mathrm{ON} / 1$ cells but be excitatory to one and inhibitory to the other. This interpretation is supported by the fact that the kinetics of IPSPS is independent of the source of elicitation (subthreshold or spike)

The application of the dye-sensitized photoinactivation technique (Miller and Selverston, 1979) to the insect central nervous system allowed us to remove one of the $\mathrm{ON} / 1$ cells from the circuit withoul physiological damage to any of the other cells, including the other $\mathrm{ON} / 1$. The elimination of one $\mathrm{ON} / 1$ cell releases the partner cell from any inhibitory influence of contralateral stimulation at calling song frequency. So far, our results confirm what has been found in earlier studies of the omega network (Wohlers and Huber, 1978, 1982; Kleindienst et al., 1981). They further demonstrate clearly that neural networks in insects can also be analyzed using the selective tool of photoinactivation.

One unexpected result of isolating an $\mathrm{ON} / 1$ cell from its contralateral partner was that instead of simply removing the inhibition, there was an unmasking of some weak excitation to contralateral stimulation. In the intact network, this cannot be observed due to the powerful inhibition generated. There are several possible sources 
A

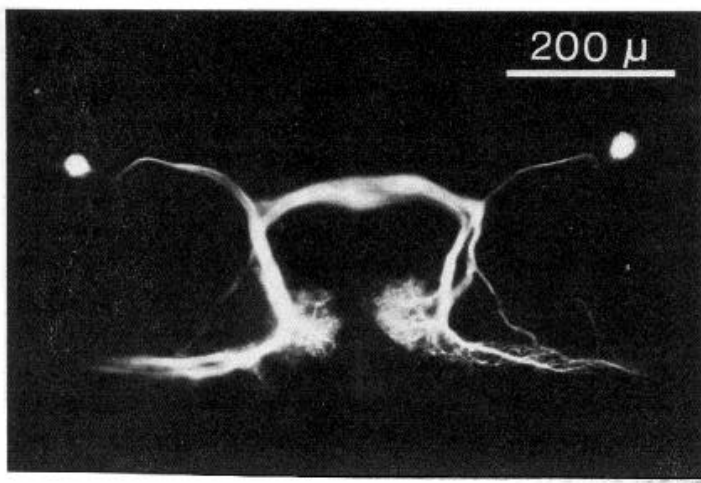

C

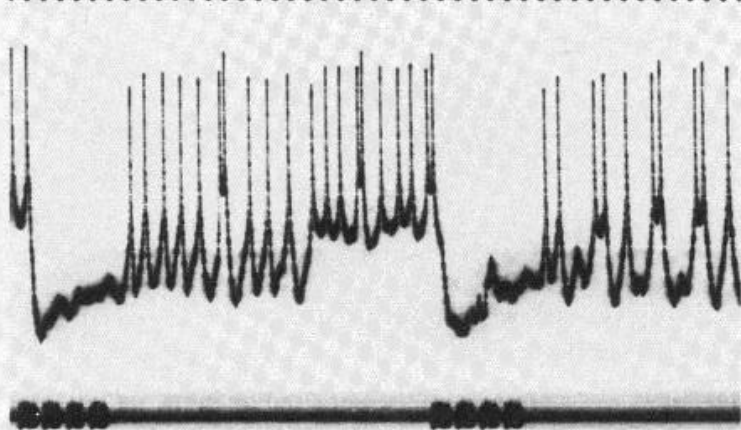

E

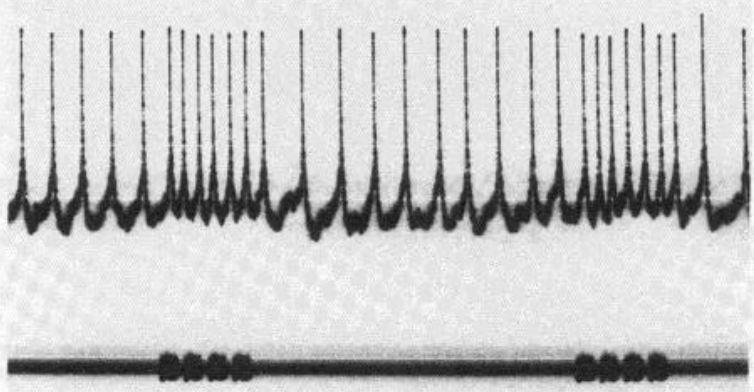

B

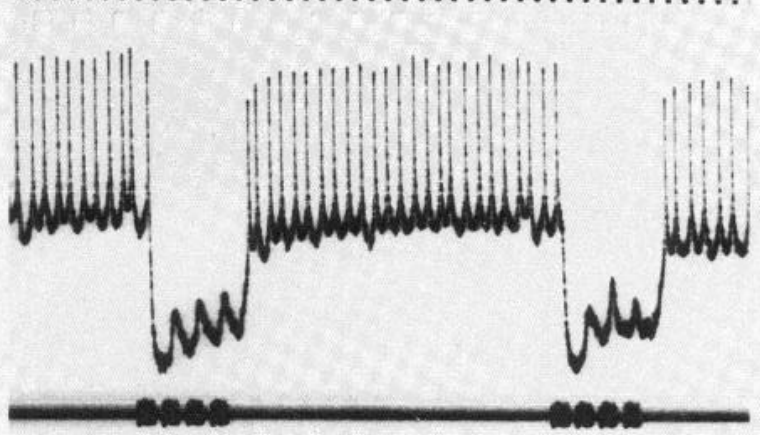

D

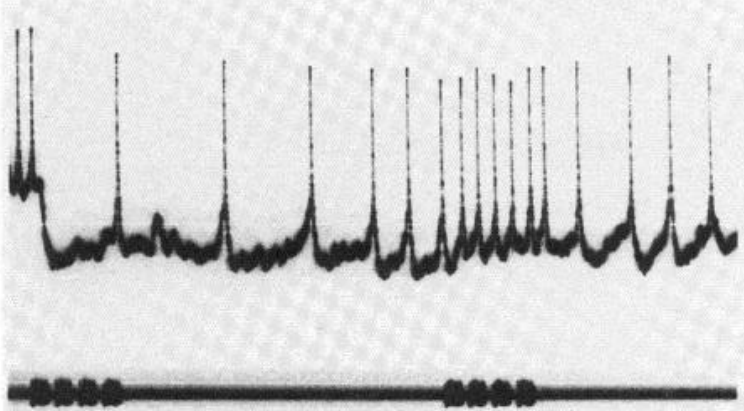

F

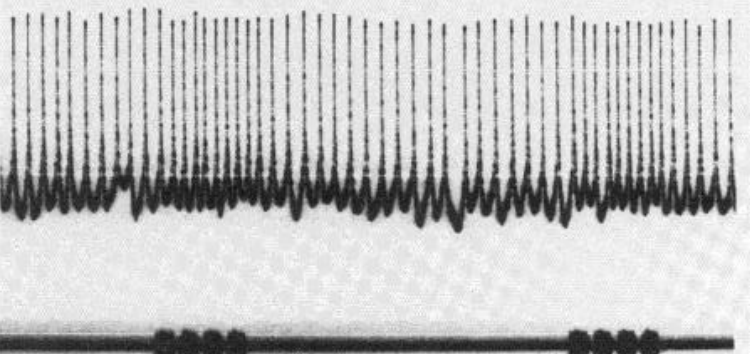

Figure 7. Photoinactivation of one $\mathrm{ON} / 1$ neuron while recording from the other (pair shown in $A$ ) removes the inhibitory response to contralateral stimulation $(5 \mathrm{kHz} 85 \mathrm{~dB}) . B$ to $D$ show the graded reduction in the summed IPSP response. $D$, in particular, shows the transition between the last inhibitory response and the weak excitatory response unmasked by the killing procedure. $E$ and $F$ are responses recorded 1 and 5 min after the end of the illumination. Time marks are $20 \mathrm{msec}$; vertical calibration is $20 \mathrm{mV}$.

of this weak excitation. The first possibility is that even though the two hearing organs were thought to be isolated by cutting the trachea, enough sound was able to reach the contralateral ear via the animal body or holder that a few efferent fibers on the opposity side were excited. That would imply that the afferent fibers involved had to have a threshold below $30 \mathrm{~dB}$ (this value is inferred from 86 $\mathrm{dB}$ stimulus intensity and $60 \mathrm{~dB}$ cross-talk reduction by curring the tracheal connection). A possible experiment to test for the activation of contralateral fibers would be to cut the auditory nerve on that side. If the weak excitation were removed by this procedure, it would be strong evidence for this external route. A second possibility is that there are some primary afferants which cross the midline and provide excitation to the opposite side. Previous work (Eibl and Huber, 1979; Esch et al., 1980) strongly suggests, however, that the primary auditory fibers do not cross over. A third possibility is that there are other interneurons mediating the weak excitation, which in intact preparations is masked by the strong $\mathrm{ON} / 1$ inhibition.
$O N / 1-A N / 2$ Interactions. From the fact that a single $\mathrm{ON} / 1$ cell is no longer inhibited by contralateral stimulation, one might also expect severe alterations in the responses of ON/1 follower cells like AN/2. One of the most common responses of $\mathrm{AN} / 2$ to auditory stimuli in the $5 \mathrm{kHz}$ range is inhibition to ipsilateral stimulation and excitation to contralateral stimulation. Because of the fact that the main processes of this neuron lie contralateral to the cell body, i.e., on the same side as the output end of the ON/ 1 cell whose cell body is ipsilateral to $\mathrm{AN} / 2$, the $\mathrm{ON} / 1$ would be a prime candidate for the source of the inhibition. As we have shown, if stimulation is delivered to the cell body side, ON/1 responds with excitation and AN/2 responds with inhibition. With stimulation delivered to the contralateral side, ON/1 responds with inhibition and $\mathrm{AN} / 2$ with excitation. Our hypothesis then was that inhibition of AN/2 results from excitation of the ipsilateral $\mathrm{ON} / 1$ and that excitation of $A N / 2$ results from primary afferents on the contralateral side. If this hypothesis is 
A

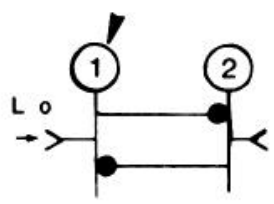

B
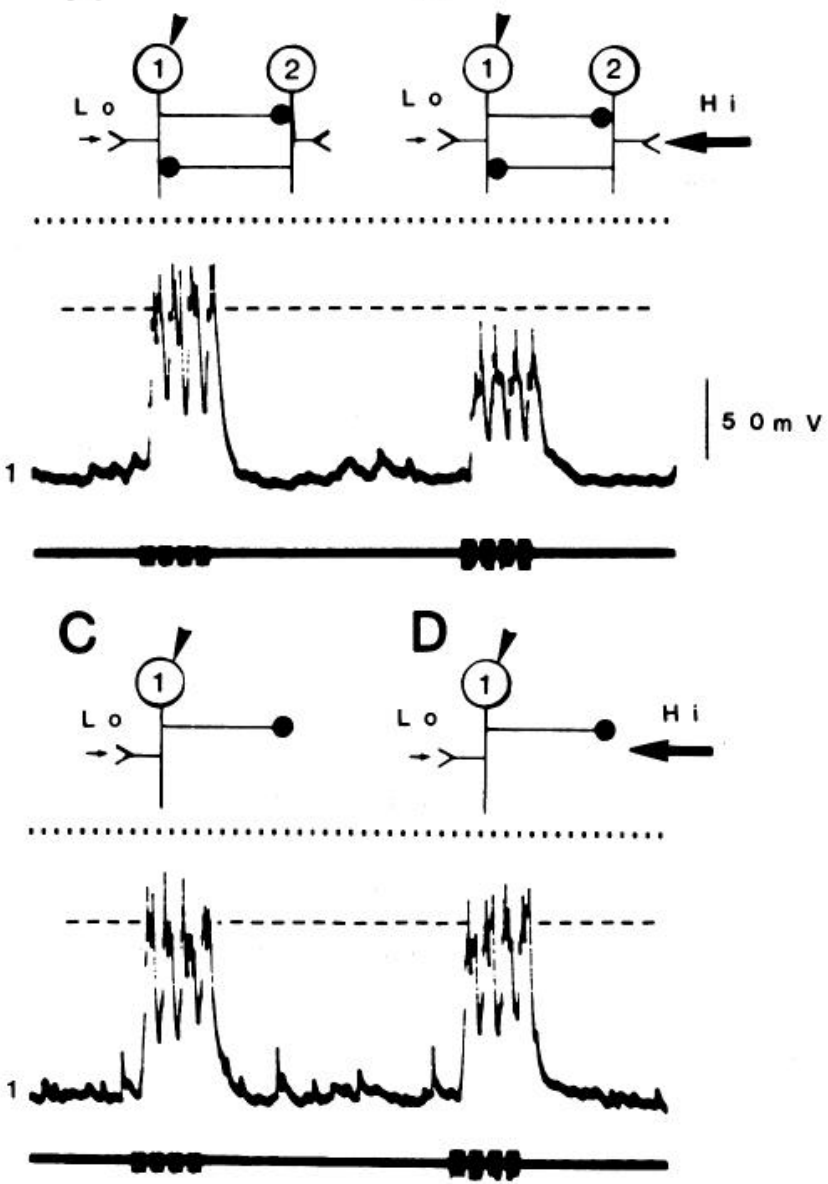

Figure 8. Functional effect of removing one $\mathrm{ON} / 1$ neuron on the activity of the other. In $A$, cell 1 is made to fire by the passage of a low-intensity stimulus ( $\mathrm{LO} 45 \mathrm{~dB}$ ) at $5 \mathrm{kHz}$ delivered to the side ipsilateral to the soma. An additional strong stimulus $(\mathrm{Hi} 95 \mathrm{~dB}$ ) delivered to the contralateral side of cell 1 activates cell 2, reducing both the number of spikes and the overall level of depolarization $(B)$. Following the killing of cell 2 , cell 1 responds as before to the same weak stimulus $(C)$ but is no longer affected by the strong contralateral stimulus $(D)$. Time marks are at 20 -msec intervals. Dashed lines help to compare stimulus-induced response levels.

correct, then killing the ipsilateral ON/1 would leave the AN/2 and the contralateral $\mathrm{ON} / 1$ functional. But inhibition caused by ipsilateral stimulation would be removed from the remaining $\mathrm{ON} / 1$ as well as the AN/2. Our results strongly support this hypothesis.

In the AN/2, the removal of inhibition by killing the ON/ 1 unmasked a weak excitatory response of about the same magnitude as seen in the ON/1. The same or similar sources as have already been discussed for the $\mathrm{ON} / 1$ cell might give rise to this response. In addition, however, the AN/2 neuron has, besides its main input branch, which is clearly contralateral to the cell body, one or more small branches exiting from the neurite on the ipsilateral side which might serve as possible sites for the generation of weak excitatory responses in the cell. The efficacy of this input may partly explain mixed inhibitory and excitatory responses, as are often seen in AN/ 2 (Wohlers and Huber, 1982).

The behavioral significance of the reciprocal inhibitory relationship between the two ON/1 cells and their inhibitory connections onto AN/2 neurons (and perhaps other ascenders) may be to provide the animal with a sound processing circuit suited to improving directional hearing. However, one cannot entirely rule out the possibility that such a circuit may also be advantageous in sharpening pattern recognition (Wiese, 1978, 1983, 1984). The role of the two ON/1 cells in sharpening laterality is much the same as lateral inhibition in

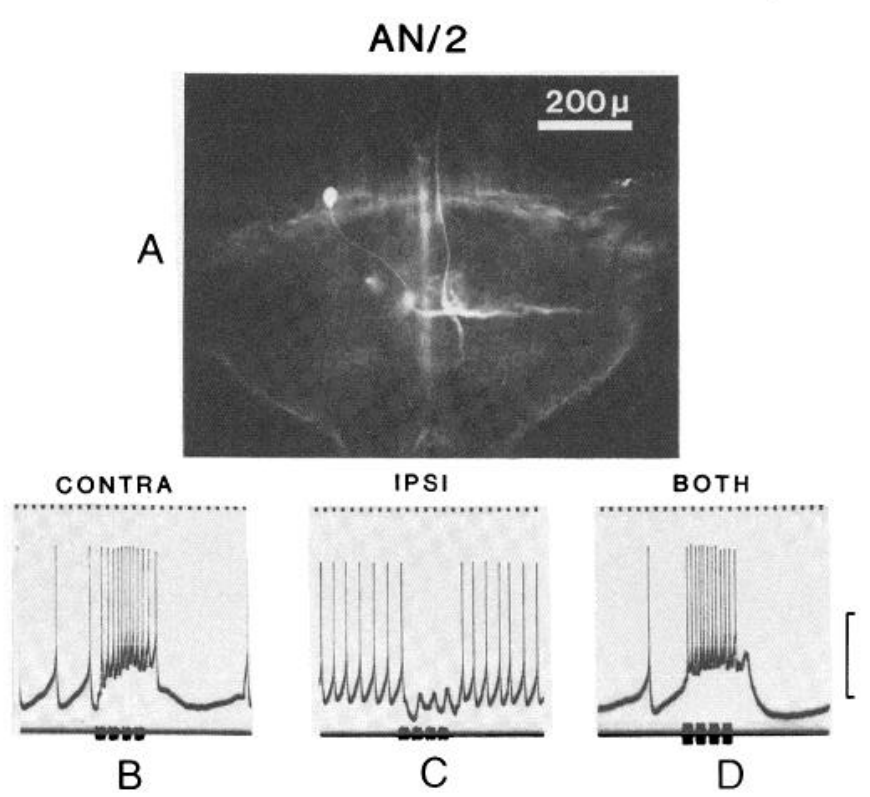

Figure 9. Common responses of AN/2 to artificial calling songs at $5 \mathrm{kHz}$ and $85 \mathrm{~dB}$. The auditory stimuli were delivered separately to each ear. Input to the contralateral side of the cell body only, which, as can be seen from the photomicrograph $(A)$, is the side of the major process and ascending axon, causes an excitatory response $(B)$. Ipsilateral stimulation only produces inhibition, shown here as summed IPSPS $(C)$. Equal stimulation of both ears produces an excitation $(D)$. Time marks are $20 \mathrm{msec}$; vertical calibration is $40 \mathrm{mV}$.

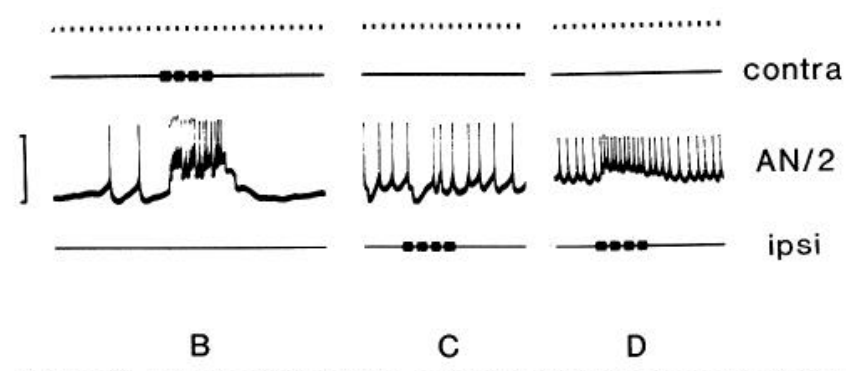

Figure 10. Effects of killing ON/1 on AN/2 in Gryllus campestris. $A$ shows the two cells involved. The lower arrow points to the neurite coming from the cell body of AN/2 which is out of focus at the upper arrow. B shows a strong AN/2 response to contralateral stimulation $(5 \mathrm{kHz}, 90 \mathrm{~dB})$. C shows an initial inhibitory response to an acoustic stimulus with the same parameters as in $B$ but delivered to the ipsilateral side. Following the $\mathrm{ON} / 1$ kill $(D)$, the amplitude of the AN/2 spikes is slightly reduced, the inhibitory response has been removed, and a weak excitatory response has been unmasked. Time marks are $20 \mathrm{msec}$; vertical calibration bar, $60 \mathrm{mV}$. 


\section{$\mathrm{ON} / 1-\mathrm{AN} / 2$}
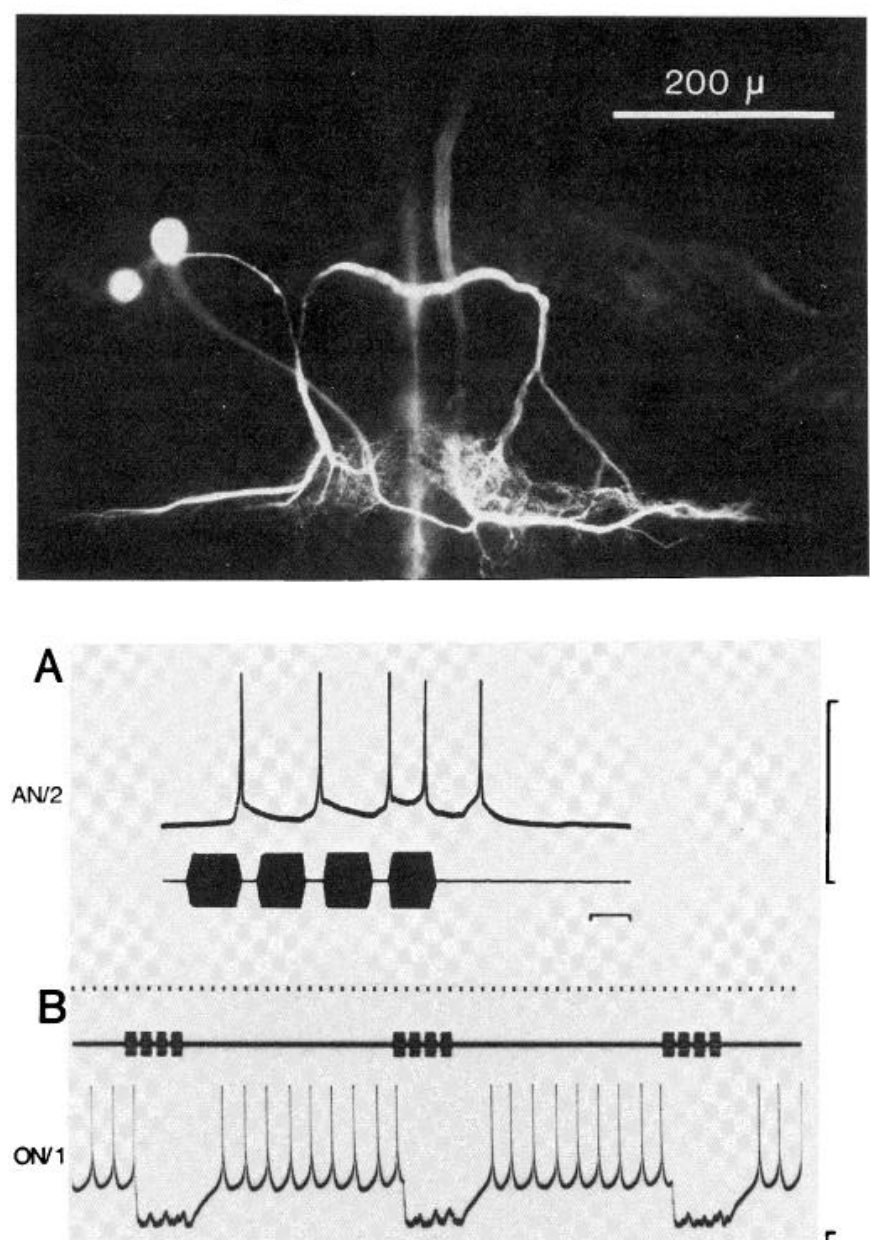

C

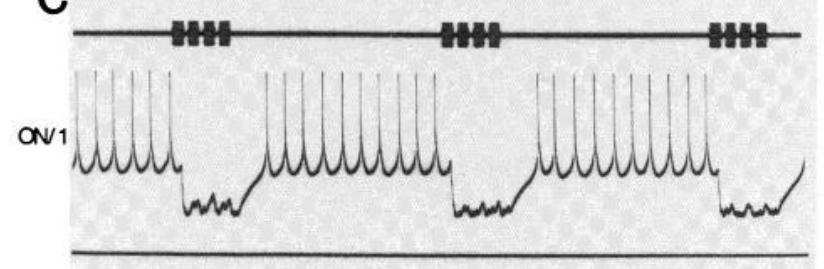

Figure 11. ON/1 inhibitory response unaffected by photoinactivation of the ipsilateral AN/2. Killing an AN/2 cell which has its major process on the same side as the output side of the ON/1 cell (microphotograph) has no effect on the inhibitory response $\mathrm{ON} / 1$ produces following contralateral stimulation. $A$ shows that contralateral stimulation to AN/2 causes an excitatory response which does not copy the syllable structure as expected (see Fig. 9). In $B, O N / 1$ is inhibited by contralateral stimulation before the AN/2 cell is killed and, as shown in $C$, this inhibition is not removed after the AN/ 2 is photoinactivated. Time marks are $20 \mathrm{msec}$; vertical calibration is $40 \mathrm{mV}$; sound stimulus, $4 \mathrm{kHz}, 85 \mathrm{~dB}$.

the eye of Limulus (Hartline and Ratliff, 1957). However, if the ON/ 1 network would not be connected to other neurons, ascending or descending elements, such binaural sharpening would be lost. Therefore, the synaptic arrangement between the ON/1 and the AN/ 2 cells provides the first clear evidence that sharpened laterality is transmitted to areas within the central nervous system that may interface with systems responsible for phonotaxis.

Changes in phonotactic responses following killing of acoustic interneurons have recently been reported (Atkins et al., 1984) and support our conclusions. Killing of a single ON/1 resulted in tracking errors when the animal was exposed to varied syllable periods, but direct orientation using syllable periods close to the conspecific call. Killing of a single AN/2 cell, however, resulted in post-test angular errors in orientation to all tested syllable periods.

\section{References}

Atkins, G. S., Ligman, F. Burghardt, and F. J. Stout (1984) Changes in phonotaxis by the female cricket Acheta domesticus $\mathrm{L}$. after killing identified acoustic interneurons. J. Comp. Physiol. A 154: 795-804.

Boyan, G. S. (1980) Auditory neurons in the brain of the cricket Gryllus bimaculatus DeGeer. J. Comp. Physiol. 140: 81-93.

Boyan, G. S. (1981) Two-tone suppression of an identified auditory neurone in the brain of the cricket Gryllus bimaculatus DeGeer. J. Comp. Physiol. 144: $117-125$.

Boyan, G. S. (1984) Neural mechanisms of auditory information processing by identified interneurones in orthoptera. J. Insect Physiol. 30: 27-41.

Boyan, G. S. and J. L. D. Williams (1982) Auditory neurones in the brain of the cricket Gryllus bimaculatus DeGeer: Ascending interneurones. J. Insect Physiol. 28: 493-501.

Boyd, P., R. Kühne, S. Silver, and B. Lewis (1984) Two-tone suppression and song coding by ascending neurones in the cricket Gryllus campestria L. J. Comp. Physiol. 154: 423-430.

Burrows, M. (1979) Graded synaptic interactions between local pre-motor interneurones of the locust. J. Neurophysiol. 42: 1108-1123.

Burrows, M. (1983) Local interneurones and the control of movement in insects. In Neuroethology and Behavioral Physiology, F. Huber and $\mathrm{H}$. Markl, eds., pp. 26-41, Springer-Verlag, New York.

Burrows, M. and M. V. S. Siegler (1978) Graded synaptic transmission between local interneurones and motor neurones in the metathoracic ganglion of the locust. J. Physiol. (Lond.) 285: 231-255.

Cassaday, G. B. and R. R. Hoy (1977) Auditory interneurons in the cricket Teleogryllus oceanicus: Physiological and anatomical properties. J. Comp. Physiol. 121: 1-13.

Eibl, E. and F. Huber (1979) Central projections of tibial sensory fibers within the three thoracic ganglia of crickets (Gryllus campestris L., Gryllus bimaculatus DeGeer). Zoomorphologie 92: 1-17.

Elsner, H. and A. V. Popov (1978) Neuroethology of acoustic communication. Adv. Insect Physiol. 13: 229-335.

Esch, H., F. Huber, and D. W. Wohlers (1980) Primary auditory neurons in crickets: Physiology and central projections. J. Comp. Physiol. 137: 2738.

Hartline, H. K. and F. Ratliff (1957) Inhibitory interaction of receptor units in the eye of Limulus. J. Gen. Physiol. 40: 357-376.

Hoy, R. R., G. S. Pollack, and A. Moiseff (1982) Species-recognition in the field cricket, Teleogryllus oceanicus: Behavioral and neural mechanisms. Am. Zool. 22: 597-607.

Huber, F. (1983) Neural correlates of orthopteran and cicada phonotaxis. In Neuroethology and Behavioral Physiology, F. Huber and H. Markl, eds., pp. 108-135, Springer-Verlag, New York.

Hutchings, M. and B. Lewis (1984) The role of two-tone suppression in song coding by ventral cord neurones in the cricket Teleogryllus oceanicus (Le Guillou). J. Comp. Physiol. 154: 103-112.

Kleindienst, H. U., U. T. Koch, and D. W. Wohlers (1981) Analysis of the cricket auditory system by acoustic stimulation using a closed sound field. J. Comp. Physiol. 141: 283-296.

Kühne, R., S. Silver, and B. Lewis (1984) Processing of vibratory and acoustic signals by ventral cord neurons in the cricket Gryllus campestris L. J. Insect Physiol. 30: 575-585.

Miller, J. P. and A. I. Selverston (1979) Rapid killing of single neurons by irradiation of intracellularly injected dye. Science 206: 702-704.

Moiseff, A. and R. R. Hoy (1983) Sensitivity to ultrasound in an identified auditory interneuron in the cricket: A possible neural link to phonotactic behavior. J. Comp. Physiol. 152: 155-167.

Pearson, K. and C. R. Fourtner (1975) Nonspiking interneurons in the walking system of the cockroach. J. Neurophysiol. 38: 33-51.

Popov, A. V. and A. M. Markovich (1982) Auditory interneurons in the prothoracic ganglion of the cricket, Gryllus bimaculatus. II. A high frequency ascending neurone (HF $A$ AN). J. Comp. Physiol. 146: 351-359.

Popov, A. V., A. M. Markovich, and A. S. Andjan (1978) Auditory interneurons in the prothoracic ganglion of the cricket, Gryllus bimaculatus DeGeer. I. The large segmental auditory neuron (LSAN). J. Comp. Physiol. 126: 183192.

Rheinlaender, J., K. Kalmring, A. V. Popov, and H. G. Rehbein (1976) Brain projections and information processing of biologically significant sounds 
by two large ventral-cord-neurons of Gryllus bimaculatus DeGeer (Orthoptera, Gryllidae). J. Comp. Physiol. 110: 251-269.

Schildberger, K. (1983) Local interneurons associated with mushroom bodies and the central body in the brain of Acheta domesticus. Cell Tiss. Res. 230: $573-586$.

Stout, J. F. and F. Huber (1972) Responses of central auditory neurons of female crickets (Gryllus campestris L.) to the calling song of the male. Z. Vergl. Physiol. 76: 302-313.

Stout, J. F. and F. Huber (1981) Responses to features of the calling song by ascending auditory interneurones in the cricket Gryllus campestris $\mathrm{L}$. Physiol. Entomol. 6: 199-212.

Wiese, K. (1978) Recurrent inhibition within the acoustic pathway of Gryllus bimaculatus as the basis of temporal filtering. Verh. Dtsch. Zool. Ges. A 168.

Wiese, K. (1981) Influence of vibration on cricket hearing: Interaction of low frequency vibration and acoustic stimuli in the omega neuron. J. Comp. Physiol. 143: 135-142.
Wiese, K. (1983) Segmentale Kommissur: Interneurons in der Hörbahn der Grille Gryllus bimaculatus DeGeer (Omega-Neurone). Habilitationsschrift der TU Braunschweig.

Wiese, K. (1984) Neural enhancement of directionality in sensory pathways of two arthropods, the cricket and the grayfish. In Localization and Orientation in Biology and Engineering, D. Varju and $\mathrm{H}$. U. Schnitzler, eds., pp. 186-191, Springer-Verlag, New York.

Wohlers, D. W. (1980) Anatomical and physiological studies of the auditory pathway in crickets. Dissertation der Universität München.

Wohlers, D. W. and F. Huber (1978) Intracellular recording and staining of cricket auditory interneurons (Gryllus campestris L., Gryllus bimaculatus DeGeer). J. Comp. Physiol. 127: 11-28.

Wohlers, D. W. and F. Huber (1982) Processing of sound signals by six types of neurons in the prothoracic ganglion of the cricket, Gryllus campestris L. J. Comp. Physiol. 127: 11-18.

Wohlers, D. W. and F. Huber (1982) Processing of sound signals by six types of neurons in the prothoracic ganglion of the cricket, Gryllus campestris L. J. Comp. Physiol. 146: 161-173. 